\title{
Herbal medicines in the treatment of coronavirus disease 2019 (COVID-19)
}

\author{
Audrey Tolouian $^{1}{ }^{\circledR}$, Maryam Khosravian $^{2}{ }^{\circledR}$, Hedieh Ragati Haghi $^{3}$, Alireza Bolourian ${ }^{4}$, Zahra \\ Mojtahedi $^{5 \oplus}$, Masoumeh Asgharpour ${ }^{6^{* \mathbb{D}}}$, Amirhesam Alirezaei ${ }^{7^{*} \mathbb{D}}$ \\ ${ }^{1}$ The University of Texas at El Paso, Texas, USA \\ ${ }^{2}$ Institute of Biology, Martin Luther University Halle-Wittenberg, Halle (Saale), Germany \\ ${ }^{3}$ School of Arts and Sciences, MCPHS University, 179 Longwood Ave, Boston, MA 02115, USA and Department of Radiology, Brigham \\ and Women's Hospital, Boston, MA 02215, USA \\ ${ }^{4}$ College of Pharmacy, Oregon State University, Corvallis, OR, USA \\ ${ }^{5}$ Department of Health Care Administration and Policy, School of Public Health, University of Nevada, Las Vegas, NV 89154, USA \\ ${ }^{6}$ Department of Nephrology, Rouhani Hospital, Babol University of Medical Sciences, Babol, Iran \\ ${ }^{7}$ Department of Nephrology, Shahid Modarres Hospital, Shahid Beheshti University of Medical Sciences, Tehran, Iran
}

\section{A R T I C L E I N F 0}

\section{Article Type:}

Review

\section{Article History:}

Received: 11 August 2020

Accepted: 7 September 2020

Published online: 2 November 2020

\section{Keywords:}

COVID-19

Herbal medicines

Flavonoids

Angiotensin-converting enzyme 2

Coronavirus disease 2019

\begin{abstract}
A B S T R A C T
Coronavirus disease 2019 (COVID-19), caused by a novel coronavirus, started in livestock within the markets of Wuhan, China and was consequently spread around the world. The virus has been rapidly spread worldwide due to the outbreak. COVID-19 is the third serious coronavirus outbreak in less than 20 years after Severe Acute Respiratory Syndrome (SARS) in 2003 and Middle East Respiratory Syndrome (MERS) in 2012. The novel virus has a nucleotide identity closer to that of the SARS coronavirus than that of the MERS coronavirus. Since there is still no vaccine, the main ways to improve personal immunity against this disease are prophylactic care and self-resistance including an increased personal hygiene, a healthy lifestyle, an adequate nutritional intake, a sufficient rest, and wearing medical masks and increasing time spent in well ventilated areas. There is a need for novel antivirals that are highly efficient and economical for the management and control of viral infections when vaccines and standard therapies are absent. Herbal medicines and purified natural products have the potential to offer some measure of resistance as the development of novel antiviral drugs continues. In this review, we evaluated 41 articles related to herbal products which seemed to be effective in the prevention or treatment of COVID-19.
\end{abstract}

Implication for health policy/practice/research/medical education:

Some herbal products seemed to be effective in the prevention or treatment of COVID-19.

Please cite this paper as: Tolouian A, Khosravian M, Ragati Haghi H, Bolourian A, Mojtahedi Z, Asgharpour M. Herbal medicines in the treatment of coronavirus disease 2019 (COVID-19). J Nephropharmacol. 2021;10(2):e18. DOI: 10.34172/ npj.2021.18.

\section{Introduction}

Coronavirus disease 2019 (COVID-19), caused by a novel coronavirus, started in livestock within the markets of Wuhan, China and was consequently spread around the world in December 2019. It can be transmitted from one person to another through sneezing or physical contact. COVID-19 mainly affects the respiratory system with symptoms such as cough, fever and shortness of breath. In most cases, the disease is mild; however, it may lead to respiratory failure in some patients, particularly in the elderly and those with co-morbidities, such as diabetes or obesity (3). When it progresses to respiratory failure or acute respiratory distress syndrome (ARDS), it often comes with multi-organ dysfunction and a disturbed immune system; in addition, it often comes with lower levels of lymphocytes, especially natural killer (NK) cells and extremely high inflammatory parameters, including C-reactive protein (CRP) and pro-inflammatory cytokines (IL-6, TNFa and IL-8) (1-3).

COVID-19 is the third serious coronavirus outbreak in less than 20 years. The first two were Severe Acute Respiratory Syndrome (SARS) in 2003 and Middle East Respiratory Syndrome (MERS) in 2012. Nucleotide identity of COVID-19 to the SARS coronavirus is almost 
$80 \%$ as compared to $52 \%$ with MERS coronavirus, that is COVID-19 is much closer in construct to the SARS coronavirus than to MERS coronavirus. Angiotensinconverting enzyme 2 (ACE2) acts as a functional receptor on the surface of cells for the entry of SARS coronavirus and COVID-19 into the body (3). At present, it is important to control the source of infection, to cut off the transmission route, and to administer effective drugs that can control the progress of the disease proactively. Currently, the drug therapy for COVID-19 is mainly comprised of four antiviral drugs, traditional medicines, immune-enhancement therapy and viral-specific plasma globulin.

Antivirals, respiratory supportive therapies and sometimes anti-inflammatory drugs have been the main treatments of severe cases of COVID-19. Promising ongoing clinical trials for COVID-19 include interferon, lopinavir/ritonavir, ribavirin, Arbidol, remdesivir, tocilizumab, glucocorticoids, IL-6 antagonist, JAK inhibitors and chloroquine/hydroxychloroquine, pseudoephedrine, rographolide, abacavir, oseltamivir and thalidomide, though none of them have shown to be universally effective (1-6). Hence, there is a vital need to discover the novel antivirals that are highly efficient and economical for the control and management of viral infections when vaccines and standard therapies are not available. Herbal medicines and purified natural products seem to play role in developing the new antiviral drugs. In this review, we evaluated herbal products that have been effective in preventing or treating COVID-19.

\section{Materials and Methods}

To collect data, a variety of sources were scrutinized such as, PubMed, Scopus, Embase, Google Scholar and Web of Science. To this end, the following keywords and their equivalents were searched through the aforementioned sources: COVID-19, herbal medicines, flavonoids, coronavirus disease 2019 and angiotensin-converting enzyme 2 .

Treatment of COVID 19 based on antiviral herbal medicine treatment

Herbal medicine is purely originated from nature, so it tends to induce fewer side effects (6). Many substances derived from plants, such as flavonoids, alkaloids, and terpenoids, have biological effects in vitro and in vivo. Along with the biological activities of the natural products derived from plants, the anti-inflammatory, antiviral, antiplatelet, antitumor, anti-allergic and antioxidant activities should also be considered. However, most of the reports have assessed the effects of these compounds in experimental models, and clinical trials are rare on this subject.

To shed some lights on this issue, there is an essential need to investigate the influence of herbal medicines on coronavirus.; In addition, the magnitude of this essence is highlighted because of rapid expansion and epidemics of COVID-19 infection, increased public concern about the transmission of the disease, lack of knowledge concerning the definitive treatment and the need for safe treatment at home. Although the review of some research articles such as one by Santana et al emphasizes the beneficial and fruitful effects of various natural products on pulmonary diseases in both experimental cases or human cases, there is not any unanimous consensus over this issue (7).

\section{Prevention}

Currently, the only way to prevent the spread of COVID-19 is infection control through hand washing, cleaning, disinfecting, sterilizing, and wearing masks. Therefore, prophylactic care or self-resistance is the main way to maintain personal immunity to the disease. Patients with underlying diseases such as hypertension, diabetes, heart disease and cancer are at higher risk due to respiratory system problems and their weak immune system responses because of their specific drug consumptions. Thus, self-resistance in these patients who constitute the most vulnerable population is of utmost importance.

Prevention of infectious diseases by traditional medicine has been recorded for many decades in Chinese history Similarly, previous studies on the prevention of SARS have been conducted by traditional Chinese medicine. Five of the most commonly used plants in traditional medicines include; astragalus, liquorice, fangfeng, baizhu and honeysuckle. In addition, other studies have shown that vitamin C, vitamin D and vitamin E supplementation, may increase resistance against coronavirus (8). Moreover, these traditional medicines are cost-effective approaches to prevent the spread of COVID 19.

Targeting ACE2 has been considered to be an alternative for preventing and inhibiting COVID-19 infection (3). Inhibiting the ACE2 receptor through using Chinese herbal medicine due to the low toxicity and high availability could be to be an alternative for treating COVID-19 (8). Molecular docking was used by Chen et al to find natural compounds for targeting the ACE2 receptor. They proposed five components with anti-virus activity including scutellarin, baicalin, hesperetin, nicotianamine and glycyrrhizin that could prevent COVID- 19 infection (9).

Among the large number of Chinese herbal components, Emodin (6-methyl-1,3,8-trihydroxyanthraquinone) was identified as an effective ingredient of polygonaceae to prevent the interaction of the SARS coronavirus protein with the ACE2 receptor and to reduce the severity of the infection. It is suggested that viral ion channels may be a good target for the development of antiviral agents. However, the pathway for the reach of the virus into its target cells is not completely blocked, and the virus may enter through other receptors, , as a result, further investigations are needed to be conducted on other cellular entry modes $(10,11)$. 
An alternative approach to the prevention of COVID-19 in high-risk populations may be based on previous evidence about viral treatments which has been proposed by traditional Chinese medicine. Huangdi's Internal Classic, an ancient Chinese book about medicine, reported about preventive effects of herbal medicine on infectious disease epidemics. In their book, Huangdi and his physician talk about the balancing of wind, heat, and dampness, which are the main principles of using Chinese medicine (12). Herbs with these historical origins used for the prevention of COVID-19 are Rhizoma Atractylodis Macrocephalae (Baizhu), Radix glycyrrhizae (Gancao), Radix saposhnikoviae (Fang Feng), Radix astragali (Huangqi), Lonicerae Japonicae Flos (Jinyinhua), and Fructus Forsythia (Lianqiao) (13).

Lau et al investigated a herbal formula (Yupingfeng Powder plus Sangju Decoction) for prevention of SARS with 16437 hospital care workers, 1063 of whom took the herbal formula (herbal group) while 15374 of whom did not (non-herbal group). None of the participants in the herbal group developed SARS disease, while $0.4 \%$ of the participants in the non-herbal group developed SARS (14). In two hospitals in Beijing, China, Xu et al (15) and Zhang et al (16) conducted studies in which a formula of Yupingfeng powder mixed with some heat-clearing and detoxifying herbs. In one hospital, 163 subjects used the powder for 6 days, and in the other hospital, 3561 subjects took it for 12- 25 days. The outcomes of these two studies revealed that none of these subjects developed SARS disease.

Treatment of cough, breathless and asthma

Traditional medicine often recommends a combination of three different strategies including lifestyle modification, herbal remedies and manual procedures for the treatment of diseases. The guidelines recommend herbal medicines alone or often in a combination. For example, a combination of Plantago major seed with its antioxidant and anti-inflammatory has effect on lungs, as well as, a combination of Almond gum with its anti-ulcerogenic has influence on the gastrointestinal epithelium, both of which were well-tolerated and deemed potentially useful for patients of 28 participants with refractory asthma in trail (17).

A murine model study assessed the effects of the Chinese herbal formula, PM014 (contains Schizandra chinensis, Stemona sessilifolia, Asparagus cochinchinensis, Rehmannia glutinosa, Scutellaria baicalensis, Prunus armeniaca, and Paeonia suffruticosa), on lipopolysaccharide induced, chronic obstructive pulmonary disease. It was confirmed that PM014 improved the lung inflammation markers and decreased accumulation of immune cells and levels of TNF- $\alpha$ and IL-6 in bronchoalveolar lavage fluid (18).

A study on 76 discharged patients in China, showed that the average time of hospitalization decreased in 59 cases after treatment with Qingfei Paidu decoction. In addition, the thoracic computed tomography scan (CAT scan) indicated the improvement of inflammatory lesions by Qingfei Paidu decoction (19). Another study revealed the treatment efficacy of Jinxin Oral Liquid (JOL), modified from Ma Xing Shi Gan decoction from traditional Chinese medicines for pneumonia and asthma (20).

Moreover, Nigella sativa was also shown to possess antiviral activity against hepatitis- $C$ infection in patients with type- 2 diabetes. In a single-arm pilot study conducted on type-2 diabetic patients, the administration of Nigella sativa, instead of interferon/ribavirin therapy, significantly reduced the viral load and improved oxidative stress and glycemic control (21). Another study showed the possible effects of Nigella sativa on immune-response and pathogenesis of influenza virus subtype H9N2 (H9N2) on 130 non-vaccinated mixed-sex turkey poults. Supplementation of Nigella sativa was found to reduce the pathogenicity of influenza viruses and increased immune responses (22). Similarly, Sinupret ${ }^{\oplus}$, another naturopathic mucolytic, has a wide range of antiviral activity in vitro against respiratory viruses (23), and Lamiaceae is one of the most important and well-known herbal families because of numerous biological and medicinal effects that could help prevent and treat some viral diseases (24).

\section{Anti-SARS herbal compounds}

Patients with SARS treated with traditional Chinese medicines have been proven to take benefit from shorter hospitalizations, fewer steroid-related side effects, and improvement of symptoms. In this field, a study by Zhang et al provided methods to identify several Chinese medicinal plants categorized as antiviral/pneumonia-effective that might directly prevent the COVID-19 infection (25). They highlighted the prospect of computer-aided and structure-based traditional Chinese medicinal drugs for the novel coronavirus pneumonia. These methods assisted in the combination and categorization of compounds into a subclass, in a short amount of time with finite resources, for the future clinical use of traditional Chinese medicinal formulas (26).

Using the molecular docking modelling, Khaerunnisa et al identified potential bioactive compounds against COVID-19 via blocking protease in some medicinal plants. The study showed nelfinavir, lopinavir, kaempferol, quercetin, luteolin-7-glucoside, demethoxycurcumin, naringenin, apigenin-7-glucoside, oleuropein, curcumin, catechin, and epicatechin-gallate acted as the best potential for COVID-19 main protease inhibitors (27).

It has also been suggested that many Indian medicinal plants with antiviral, anti-inflammatory and antioxidant properties could be favorable for the treatment of COVID 19. However, standard clinical trials are needed to prove the efficacy of these herbs to manage the immune system. Glycyrrhiza glabra, Allium sativum, Clerodendrum inerme Gaertn, and Strobilanthes cusia seem to be alternative candidates against COVID-19 by targeting the viral 
replication of SARS coronavirus, inactivating the viral ribosome, blocking the viral RNA genome synthesis and inducing protease activity (28). Keyaerts et al evaluated a special collection of 33 plant lectins with different specificities. Herbal lectins presented a selective and potent anti-coronavirus activity by interfering in the viral replication cycle (29).

In their review, Lin et al found that several natural and herbal medicines had antiviral effects on COVID-19. These herbs included: Artemisia annua, Lycoris radiata, Pyrrosia lingua, and Lindera aggregata, Isatis indigotica, Torreya nucifera, myricetin, scutellarin and Houttuynia cordata (30). Another study showed that viral loads and replication of SARS coronavirus were decreased after treatment with Anthemis hyalina, Nigella sativa and peels of Citrus sinensis extracts. Anthemis hyalina extract is the best candidate and could be used in highly effective drugs against coronavirus and other viruses. In addition, a mixture of Nigella sativa and honey has the ability to improve respiratory tract infections (31).

The development of anti-SARS coronavirus agents is essential to combat the pandemic of COVID- 19. Using a cell-based assay on Vero E6 cells measuring SARS coronavirus induced cytopathogenic effect in vitro, Wen et al tested over 200 Chinese medicinal extracts. Six herbal extracts, one from Gentianae radix, Dioscoreae rhizoma, Cassiae semen and Loranthi ramus and two from Rhizoma Cibotii, were found to be potent inhibitors of SARScoronavirus (32). Several important herbal resources against SARS coronavirus are summarized in Table 1.

Herbals with beneficial effects on inflammatory markers like Allium sativum and Ocimum basilicum may be effective in the treatment of inflammatory phase of COVID-19 (42).

\section{Conclusion}

Currently, there are no specific vaccines or antiviral treatments for COVID-19 and no vaccine is expected to be ready for months. A discovery of novel antivirals which are highly efficient and economical for the supervision and control of viral infections are absolutely essential in the absence of vaccines and standard therapies. Therefore prophylactic care and self-resistance are the main ways to preserve personal protection and immunity. Furthermore, the development of anti-SARS coronavirus herbal agents seems to be inevitable in protecting against the COVID -19 pandemic disease because of the structural similarity of these two viruses.

\section{Authors' contribution}

AA and MA prepared the primary draft. MK, HRH, RT and AT completed and extended the manuscript. $\mathrm{AB}$ and $\mathrm{ZM}$ edited the paper. AA finalized the paper. All authors read and signed the final manuscript.

\section{Conflicts of interest}

The authors declared no competing interests.

\section{Ethical considerations}

Ethical issues (including plagiarism, data fabrication, double publication) have been completely observed by the authors.

Funding/Support

None.

\section{References}

1. Asgharpour M, Zare E, Mubarak M, Alirezaei A. COVID-19 and Kidney Disease: Update on Epidemiology, Clin-ical Manifestations, Pathophysiology and Management. J Coll Physicians Surg Pak 2020;30:S19-S25.

2. Zhang W, Zhao Y, Zhang F, Wang Q, Li T, Liu Z, et al. The use of anti-inflammatory drugs in the treatment of people with severe coronavirus disease 2019 (COVID-19): The experience of clinical immunologists from China.

Table 1. Some important herbal resource against SARS coronavirus

\begin{tabular}{|c|c|c|}
\hline Plant & Component & Reference \\
\hline Cinnamomi Cortex & Procyanidins and butanol & (33) \\
\hline Isatis indigotica root extrac & Two phenolic compounds aloe emodin and hesperetin & (34) \\
\hline Tylophorine compounds & $\begin{array}{l}\text { Naturally and synthetic phenanthroindolizidines and } \\
\text { phenanthroquinolizidines }\end{array}$ & (35) \\
\hline Houttuynia cordata Thunb. (Saururaceae) (HC) & & (36) \\
\hline Echinace and Lycoris radiate & & (37) \\
\hline Indometachin & & (38) \\
\hline Toona sinensis Roem, & & (39) \\
\hline A. annua, L. radiata, P. lingua, and L. aggregata & lycorine & (40) \\
\hline Cimicifuga rhizoma, Meliae cortex, Coptidis rhizoma, and Phellodendron cortex & & $(41)$ \\
\hline $\begin{array}{l}\text { Six herbal extracts, one each from Gentianae Radix, Dioscoreae Rhizoma, } \\
\text { Cassiae Semen and Loranthi Ramus and two from Rhizoma Cibotii }\end{array}$ & & $(32)$ \\
\hline Viral ion channels of emodin & & (10) \\
\hline $\begin{array}{l}\text { Anthemis hyalina (Ah), Nigella sativa (Ns) and peels of Citrus sinensis (Cs) } \\
\text { extracts }\end{array}$ & & (31) \\
\hline
\end{tabular}


Clin Immunol. 2020;214:108393. doi: 10.1016/j. clim.2020.108393.

3. Bolourian A, Mojtahedi Z. Obesity and COVID-19: The mTOR pathway as a possible culprit. Obes Rev. 2020;21: e13084. doi: 10.1111/obr.13084

4. Sohrabi C, Alsafi Z, O'Neill N, Khan M, Kerwan A, AlJabir A, et al. World Health Organization declares global emergency: a review of the 2019 novel coronavirus (COVID-19). Int J Surg. 2020;76:71-6. doi: 10.1016/j. ijsu.2020.02.034

5. Lai CC, Liu YH, Wang CY, Wang YH, Hsueh SC, Yen MY, et al. Asymptomatic carrier state, acute respiratory disease, and pneumonia due to severe acute respiratory syndrome coronavirus 2 (SARS-CoV-2): Facts and myths. J Microbiol Immunol Infect. 2020. doi: 10.1016/j.jmii.2020.02.012.

6. Li X, Yu J, Zhang Z, Ren J, Peluffo AE, Zhang W, et al. Network bioinformatics analysis provides insight into drug repurposing for COVID-2019. Preprints 2020; 2020030286. doi: 10.20944/preprints202003.0286.v1.

7. Dudani T, Saraogi A. Use of herbal medicines on coronavirus. Acta Sci pharm Sci. 2020; 4.4: 61-63.

8. Santana FP, Pinheiro NM, Mernak MI, Righetti RF, Martins MA, Lago JH, et al. Evidences of Herbal MedicineDerived Natural Products Effects in Inflammatory Lung Diseases. Mediators Inflamm. 2016;2016:2348968. doi: 10.1155/2016/2348968.

9. Wang LS, Wang YR, Ye DW, Liu QQ. Review of the 2019 novel coronavirus (COVID-19) based on current evidence. Int J Antimicrob Agents. 2020;55:105948. doi: 10.1016/j. ijantimicag.2020.105948.

10. Chen $\mathrm{H}, \mathrm{Du}$ Q. Potential Natural Compounds for Preventing SARS-CoV-2 (2019-nCoV) Infection. Preprints 2020; 2020010358. doi: 10.20944/preprints202001.0358.v3.

11. Schwarz S, Wang K, Yu W, Sun B, Schwarz W. Emodin inhibits current through SARS-associated coronavirus 3a protein. Antiviral Res. 2011;90:64-9. doi: 10.1016/j. antiviral.2011.02.008

12. Curran J. The yellow emperor's classic of internal medicine. BMJ. 2008;336:777. doi: 10.1136/bmj.39527.472303.4E

13. Luo H, Tang QL, Shang YX, Liang SB, Yang M, Robinson $\mathrm{N}$, et al. Can Chinese medicine be used for prevention of corona virus disease 2019 (COVID-19)? A review of historical classics, research evidence and current prevention programs. Chin J Integr Med. 2020;26:243-50. doi: 10.1007/ s11655-020-3192-6.

14. Lau J, Leung P, Wong E, Fong C, Cheng K, Zhang S, et al. The use of an herbal formula by hospital care workers during the severe acute respiratory syndrome epidemic in Hong Kong to prevent severe acute respiratory. J Alternat Complement Med. 2005;11:49-55. doi: 10.1089/acm.2005.11.49.

15. Xu J, Jiang X, Liu F, Zhang W. Clinical observation of Yinhua Yupingfeng Decoction in preventing SARS: analysis of 163 first-line medical staff. Conference on the prevention and treatment of SARS in integrated traditional Chinese and Western medicine in five provinces of North China; 2006; Beijing. p. 158-9.

16. 16.Zhang L, Chen B, Zeng H. Analysis of fangdu decoction on SARS and zero infection in hospital. Chin J Hosp Pharm (Chin). 2005;25:59-60.

17. Anushiravania M, JabbariAzad F, Taghipour A, Mirsadraeed
M, Afshari TJ, Salari R, et al. The effect of Plantago major seed and Almond gum on refractory asthma: A proof-ofconcept study. J Herb Med. 2020;19:100297. doi: 10.1016/j. hermed.2019.100297

18. Lee H, Kim Y, Kim HJ, Park S, Jang YP, Jung S, Jung H, Bae H. Herbal Formula, PM014, Attenuates lung inflammation in a murine model of chronic obstructive pulmonary disease. Evid Based Complement Alternat Med. 2012;2012:769830. doi: 10.1155/2012/769830.

19. Liu N, Li S, Fan K, Lu T, Li T. The prevention and treatment of COVID-19 with Qingfei Paidu decoction in Shanxi China. TMR Modern Herbal Medicine. 2020;3:1-5. doi: 10.12032/TMRmhm202003066.

20. Lin L, Yan H, Chen J, Xie H, Peng L, Xie T, et al. Application of metabolomics in viral pneumonia treatment with traditional Chinese medicine. Chin Med. 2019;4:8. doi: 10.1186/s13020-019-0229-x.

21. Barakat EMF, El-Wakeel LM, Hagag RS. Effects of Nigella sativa on outcome of hepatitis C in Egypt. World J Gastroenterol. 2013;19: 2529-2536. doi: 10.3748/wjg.v19. i16.2529.

22. Umar S, Munir MT, Subhan S, Azam T, Nisa Q, Khan MI, et al. Protective and antiviral activities of Nigella sativa against avian influenza (H9N2) in turkeys. J Saudi Soc Agric Sci 2016. doi: 10.1016/j.jssas.2016.09.004

23. Glatthaar-Saalmüller B, Rauchhaus U, Rode S, Haunschild J, Saalmüller A. Antiviral activity in vitro of two preparations of the herbal medicinal product Sinupret ${ }^{\circledR}$ against viruses causing respiratory infections. Phytomedicine. 2011;19:1-7. doi: 10.1016/j.phymed.2011.10.010.

24. Bekut M, Brkić S, Kladar N, Dragović G, Gavarić N, Božin B. Potential of selected Lamiaceae plants in anti(retro)viral therapy. Pharmacol Res. 2018;133:301-14. doi: 10.1016/j. phrs.2017.12.016.

25. Zhang $\mathrm{D}, \mathrm{Wu} \mathrm{K}$, Zhang $\mathrm{X}$, Deng $\mathrm{S}$, Peng B. In silico screening of Chinese herbal medicines with the potential to directly inhibit 2019 novel coronavirus. J Integr Med. 2020;18:152-8. doi: 10.1016/j.joim.2020.02.005.

26. Ling CQ.Traditional Chinese medicine is a resource for drug discovery against 2019 novel coronavirus (SARS-CoV-2). J Integr Med. 2020;18:87-8. doi: 10.1016/j.joim.2020.02.004.

27. Khaerunnisa S, Kurniawan H, Awaluddin R, Suhartati S, Soetjipto S. Potential inhibitor of COVID-19 main protease (Mpro) from several medicinal plant compounds by molecular docking study. Preprints 2020;2020030226. doi: 10.20944/preprints202003.0226.v1.

28. Vellingiri B, Jayaramayya K, Iyer M, Narayanasamy A, Govindasamy V, Giridharan B, et al. COVID-19: A promising cure for the global panic. Sci Total Environ. 2020;725:138277. doi: 10.1016/j.scitotenv.2020.138277.

29. Keyaerts E, Vijgen L, Pannecouque C, Van Damme E, Peumans W, Egberink $\mathrm{H}$, et al. Plant lectins are potent inhibitors of coronaviruses by interfering with two targets in the viral replication cycle. Antiviral Res. 2007;75:179-87. doi: 10.1016/j.antiviral.2007.03.003.

30. Lin LT, Hsu WC, Lin CC. Antiviral natural products and herbal medicines. J Tradit Complement Med. 2014;4:24-35. doi: 10.4103/2225-4110.124335.

31. Ulasli M, Gurses SA, Bayraktar R, Yumrutas O, Oztuzcu S, Igci M, et al. The effects of Nigella sativa (Ns), Anthemis 
hyalina (Ah) and Citrus sinensis (Cs) extracts on the replication of coronavirus and the expression of TRP genes family. Mol Biol Rep. 2014;41:1703-11. doi: 10.1007/ s11033-014-3019-7.

32. Wen CC, Shyur LF, Jan JT, Liang PH, Kuo CJ, Arulselvan $\mathrm{P}$, et al. Traditional Chinese medicine herbal extracts of Cibotium barometz, Gentiana scabra, Dioscorea batatas, Cassia tora, and Taxillus chinensis inhibit SARS-CoV replication. J Tradit Complement Med. 2011;1:41-50. doi: 10.1016/s2225-4110(16)30055-4.

33. Zhuang M, Jiang H, Suzuki Y, Li X, Xiao P, Tanaka T, et al. Procyanidins and butanol extract of Cinnamomi Cortex inhibit SARS-CoV infection. Antiviral Res. 2009;82:73-81. doi: 10.1016/j.antiviral.2009.02.001.

34. Lin CW, Tsai FJ, Tsai CH, Lai CC, Wan L, Ho TY, Hsieh CC, Chao PD. Anti-SARS coronavirus 3C-like protease effects of Isatis indigotica root and plant-derived phenolic compounds. Antiviral Res. 2005;68:36-42.

35. Yang CW, Lee YZ, Kang IJ, Barnard DL, Jan JT, Lin $\mathrm{D}$, et al. Identification of phenanthroindolizines and phenanthroquinolizidines as novel potent anti-coronaviral agents for porcine enteropathogenic coronavirus transmissible gastroenteritis virus and human severe acute respiratory syndrome coronavirus. Antiviral Res. 2010;88:160-8. doi: 10.1016/j.antiviral.2010.08.009.

36. Lau KM, Lee KM, Koon CM, Cheung CS, Lau CP, Ho $\mathrm{HM}$, et al. Immunomodulatory and anti-SARS activities of Houttuynia cordata. J Ethnopharmacol. 2008;118:79-85. doi: $10.1016 /$ j.jep.2008.03.018.

37. Gautam P. Antiviral potential of medicinal plants: an overview. Int Res J Pharm. 2013;4:8-16 doi: 10.7897/22308407.04603.

38. Amici C1, Di Caro A, Ciucci A, Chiappa L, Castilletti C, Martella $\mathrm{V}$, et al. Indomethacin has a potent antiviral activity against SARS coronavirus . Antivir Ther. 2006;11:1021-30.

39. Chen CJ, Michaelis M, Hsu HK, Tsai CC, Yang KD, Wu YC, et al. Toona sinensis Roem tender leaf extract inhibits SARS coronavirus replication. J Ethnopharmacol. 2008;120:10811. doi: 10.1016/j.jep.2008.07.048.

40. Li SY, Chen C, Zhang HQ, Guo HY, Wang H, Wang L, Identification of natural compounds with antiviral activities against SARS-associated coronavirus. Antiviral Res. 2005;67:18-23.

41. Kim HY, Shin HS, Park H, Kim YC, Yun YG, Park S, Shin HJ, Kim K. In vitro inhibition of coronavirus replications by the traditionally used medicinal herbal extracts, Cimicifuga rhizoma, Meliae cortex, Coptidis rhizoma, and Phellodendron cortex. J Clin Virol. 2008;41:122-8. doi: 10.1016/j.jcv.2007.10.011.

42. Zare E, Alirezaei A, Bakhtiyari M, Mansouri A. Evaluating the effect of garlic extract on serum inflammatory markers of peritoneal dialysis patients: a randomized double-blind clinical trial study. BMC Nephrol. 2019;20:26. doi: 10.1186/ s12882-019-1204-6.

Copyright $\odot 2021$ The Author(s); Published by Published by Society of Diabetic Nephropathy Prevention. This is an open-access article distributed under the terms of the Creative Commons Attribution License (http://creativecommons.org/licenses/by/4.0), which permits unrestricted use, distribution, and reproduction in any medium, provided the original work is properly cited. 